\title{
Gravity Modeling of Turkey's International Trade under Globalization
}

\author{
Asst. Prof. Dr. Ayşen Hiç Gencer (Istanbul Aydın University, Turkey)
}

\begin{abstract}
Gravity modeling in international trade is developed by Tinbergen and Poyhonen in the 1960s, inspired by Newton's standard gravity formulation. This model suggests that the volume of trade between two countries is proportional to the product of their national income and inversely proportional to the distance between them. This study attempts to answer the question whether the gravity model is still valid for the case of Turkey today in the age of globalization and declining transportation costs due to improvements in logistics and technology. To this end, Turkey's imports as well as exports data with respect to all the countries of the world for the 16 years between 1993 and 2008 are analyzed. The results show that the gravity model, even in its basic form, is still powerful in explaining the trade volumes between Turkey and all other countries. In addition, the basic model is extended to analyze Turkey's trade with specific country groups such as the EU countries, the Islamic countries, the former Soviet Union countries, and the Central Asian countries. The analysis concludes that except for the Central Asian countries, Turkey's trade is not specialized with any particular country group. The 1995 Customs Union with the EU or any other step already taken towards full membership into the EU has not significantly increased Turkey's trade volume with the EU members over the amounts predicted by the basic version of the gravity model for any country pair of similar distance and GDP levels.
\end{abstract}

JEL codes: F17, F10

\section{Gravity Modeling in International Trade and Globalization}

Gravity modeling in international trade was developed by Tinbergen (1962) and Poyhonen (1963) in the 1960s, inspired by Newton's standard gravity formulation. As in Newton's gravity equation, where the force between two bodies is proportional to the product of their masses and inversely proportional to the distance between them, this model also suggests that the volume of trade between two countries will be proportional to the product of their national income, and inversely proportional to the distance between them. Deardorff (1995) demonstrated that the gravity model is, indeed, compatible with the traditional Ricardian or Heckscher-Ohlin models, as well.

The model implies that the greater the product of two country's income and the closer they are to each other, the greater will be the volume of trade between them. For the case of the exporting country, the national income gives an indication of its exportable surplus. For the case of the importing country, it gives an indication of its purchasing power.

However, today, we live in a vastly different world compared to the time when the gravity model was developed. The catch phrase that characterizes this new era is globalization. The major defining feature of globalization is the widespread implementation of open economy and free international trade. Another defining feature is the increased flow of financial funds and credits and the increased volume of direct private investments, as well as freer cross-border movements of workers and flow of workers' remittances. The most relevant defining feature of globalization with respect to the gravity modeling is that improvements in logistics and multi-modal transportation led to dramatic declines in transportation costs, and opened up new markets both for exports and imports.

As a result, the trade volume of the world as a whole has increased from 5.5\% of world GDP in 1950 to $17.2 \%$ of world GDP in 1998 (Madison, 2001). Moreover, the composition of traded goods shifted away from agricultural and mineral products towards mainly manufactured products (WTO, 2008). In addition, new trade directions emerged: In the past, international trade took place mainly among developed countries. Today, trade takes place among developing and less developed countries with developed countries as well.

In light of these developments, the question addressed in this study is whether the gravity model is still adequate in explaining Turkey's international trade patterns.

\section{Model and Variables}

The basic gravity model has the form:

$$
T_{i j}=K \frac{Y_{i}^{\alpha_{M}} Y_{j}^{\alpha_{X}}}{d_{i j}^{\delta}} u_{i j}
$$

where:

- $\mathrm{T}_{\mathrm{ij}}$ : Exports (imports) of the $\mathrm{j}^{\text {th }}$ country to (from) the $\mathrm{i}^{\text {th }}$ country. 
- $\mathrm{Y}_{\mathrm{i}}$ : Income of the $\mathrm{i}^{\text {th }}$ country.

- $Y_{j}$ : Income of the $j^{\text {th }}$ country.

- $\mathrm{d}_{\mathrm{ij}}$ : Distance between $\mathrm{i}^{\text {th }}$ country and the $\mathrm{j}^{\text {th }}$ country.

- $\mathrm{K}$ : Proportionality constant.

- $\alpha_{M}$ : Role of the importing country's size.

- $\alpha_{X}$ : Role of the exporting country's size.

- $\gamma$ : Role of the distance between them.

- $\mathrm{u}_{\mathrm{ij}}$ : Multiplicative error term.

In this study, there is only one exporting (or importing) country, namely Turkey. Therefore, $\mathrm{Y}_{\mathrm{i}} \mathrm{is}$ constant in all country pairs, hence it must be absorbed in the $\mathrm{K}$ term. So, the model becomes:

For imports: $\quad M_{j}=K_{M} \frac{Y_{j}^{\alpha_{M}}}{d_{j}^{\delta_{M}}} u_{j}$

For exports: $\quad X_{j}=K_{X} \frac{Y_{j}^{\alpha_{X}}}{d_{j}^{\delta_{X}}} u_{j}$

In order to employ the OLS regression method, the model must be linearized by taking the logarithm of the equations:

$$
\begin{aligned}
\ln M_{j} & =\ln K_{M}+\alpha_{M} \ln Y_{j}+\delta_{M} \ln d_{j}+u_{j} \\
\ln X_{j} & =\ln K_{X}+\alpha_{X} \ln Y_{j}+\delta_{X} \ln d_{j}+u_{j}
\end{aligned}
$$

In order to avoid any auto-correlation issues, a separate cross-sectional OLS regression is performed for each period of time. This also allows for an analysis of the evolution of Turkey's trade patterns.

\section{Data and Sources}

In this study, Turkey's imports and exports data for the 16 years between 1993 and 2008 are analyzed. The reason 1993 is chosen to be the initial point of time is that it is the first year when the former Soviet Union countries started gathering individual data on international trade after gaining their sovereignty around 1990. The reason 2008 is chosen to be the final point of time is that it is the year when the global economic and financial crisis and recession broke out resulting in a systematic shift in the world economic data.

Turkey's imports and exports data are taken from the Undersecretary of Turkish Foreign Trade (2011). The data lists Turkey's imports and exports volumes in current prices in million US dollars for the years 1990-2010 with 292 countries, regions and free trade zones. However, in the analysis only countries with non-zero trade volumes could be taken into consideration due to the mathematical fact that the logarithm of zero being undefined.

GDP data are taken from the United Nations National Accounts Database (2011). In this study, GDP data in current prices is utilized rather than GDP calculated according to purchasing power parity or GDP in real prices. GDP calculated according to purchasing power parity is generally not used in international trade studies, since prices are assumed to be homogeneous in international trade markets. GDP in real prices is also not chosen in this study, since the trade data are in current prices and no year-over-year comparisons are made.

The gravity model employs the geographical distance between two countries as a proxy for transportation costs. Since countries do not consist of a single point, the geographical centers of two countries are chosen as reference points and the length of the line between these two points is taken from MapCrow (2011). It would be more prudent to use the center of economic activity for each country, however such data is not readily available for most countries.

\section{Results of the Basic Gravity Model}

Table 1 summarizes the results of the 32 OLS regressions performed separately for each of the 16 years for imports as well as for exports.

The results clearly show that the gravity model, even in its basic version, is still valid in the age of globalization. For all the years studied and for both imports and exports, $\mathrm{R}^{2}$ is between 0.7 and 0.8 . GDP coefficients are all positive and distance coefficients are all negative, as postulated by the model. Most importantly, all coefficients for all years are statistically significant at $1 \%$ level.

Comparing imports with exports, one can notice that the coefficient of distance is larger in magnitude (more negative) for exports relative to imports. This is due to the fact that Turkey's exports mainly consist of perishable agricultural products traded with nearby countries. 
Looking at systematic changes over years, it can be observed that no significant variation occurred both in the coefficients of GDP and distance as well as in $\mathrm{R}^{2}$ over the years studied.

\begin{tabular}{|c|c|c|c|c|c|c|c|c|c|c|c|c|}
\hline \multirow{3}{*}{$\frac{\text { YEAR }}{1993}$} & \multicolumn{6}{|c|}{ IMPORTS } & \multicolumn{6}{|c|}{ EXPORTS } \\
\hline & $\mathbf{N}$ & $\mathbf{R}^{2}$ & \multicolumn{2}{|c|}{ GDP } & \multicolumn{2}{|c|}{ DISTANCE } & $\mathbf{N}$ & $\mathbf{R}^{2}$ & \multicolumn{2}{|c|}{ GDP } & \multicolumn{2}{|c|}{ DISTANCE } \\
\hline & 107 & 0.715 & 0.924 & $(0.058)$ & -0.827 & $(0.142)$ & 145 & 0.694 & 0.975 & $(0.066)$ & -1.831 & $(0.170)$ \\
\hline 1994 & 107 & 0.764 & 0.956 & $(0.053)$ & -0.972 & $(0.132)$ & 145 & 0.737 & 1.069 & $(0.062)$ & -1.800 & $(0.164)$ \\
\hline 1995 & 112 & 0.753 & 0.977 & $(0.055)$ & -1.052 & $(0.139)$ & 148 & 0.719 & 0.975 & $(0.059)$ & -1.621 & $(0.156)$ \\
\hline 1996 & 117 & 0.740 & 0.925 & $(0.053)$ & -0.897 & $(0.131)$ & 146 & 0.752 & 0.902 & $(0.052)$ & -1.617 & $(0.136)$ \\
\hline 1997 & 118 & 0.732 & 0.989 & $(0.058)$ & -0.994 & $(0.140)$ & 148 & 0.725 & 0.867 & $(0.053)$ & -1.537 & $(0.137)$ \\
\hline 1998 & 115 & 0.789 & 1.039 & $(0.0$ & -1.038 & $(0.130)$ & 152 & 0.714 & 0.895 & $(0$. & -1.519 & $(0.145)$ \\
\hline 1999 & 113 & 0.759 & 0.968 & $(0.0$ & -0.930 & $(0.1$ & 151 & 0.735 & 0.944 & $(0$. & -1.538 & $(0.143)$ \\
\hline 2000 & 121 & 0.784 & 1.032 & $(0.053)$ & -1.221 & $(0.13$ & 152 & 0.785 & 0.878 & $(0.045)$ & -1.496 & $(0.117)$ \\
\hline 2001 & 110 & 0.714 & 0.974 & $(0.062)$ & -1.051 & $(0.152)$ & 153 & 0.759 & 0.903 & $(0.049)$ & -1.522 & $(0.129)$ \\
\hline 2002 & 119 & 0.727 & 1.004 & $(0.059)$ & -1.050 & $(0.147)$ & 154 & 0.752 & 0.884 & $(0.050)$ & -1.571 & $(0.131)$ \\
\hline 2003 & 125 & 0.743 & 1.002 & $(0.056)$ & -0.967 & $(0.140)$ & 155 & 0.746 & 0.856 & $(0.051)$ & -1.654 & $(0.133)$ \\
\hline 2004 & 130 & 0.738 & 1.033 & $(0.057)$ & -0.927 & $(0.143)$ & 155 & 0.770 & 0.855 & $(0.048)$ & -1.613 & $(0.125)$ \\
\hline 2005 & 132 & 0.781 & 1.061 & $(0.053)$ & -1.088 & $(0.130)$ & 155 & 0.769 & 0.818 & $(0.047)$ & -1.644 & $(0.122)$ \\
\hline 2006 & 135 & 0.778 & 1.142 & $(0.056)$ & -1.004 & $(0.138)$ & 155 & 0.786 & 0.828 & $(0.044)$ & -1.585 & $(0.116)$ \\
\hline 2007 & 137 & 0.780 & 1.148 & $(0.056)$ & -1.044 & $\begin{array}{l}(0.138) \\
\end{array}$ & 155 & 0.761 & 0.801 & $\begin{array}{l}(0.048) \\
\end{array}$ & -1.663 & $(0.125)$ \\
\hline 2008 & 137 & 0.763 & 1.132 & $(0.058)$ & -0.995 & $(0.143)$ & 155 & 0.725 & 0.792 & $(0.051)$ & -1.512 & $(0.132)$ \\
\hline
\end{tabular}

Table 1: Results of basic gravity model analysis

\section{Extended Gravity Model with Specific Country Groups}

Gravity model tries to explain the trade volume of two countries only by their economic size and geographical distance between them. However, sometimes there are special factors among countries that can enhance or retard the trade volume between specific country pairs. Examples of factors enhancing trade include common language, culture or religion, historic ties and free trade agreements. Factors that retard trade include state of war, embargoes or historic enmities.

Such factors are incorporated into the basic gravity model by employing dummy variables:

$$
\begin{gathered}
\ln M_{j}=\ln K_{M}+\alpha_{M} \ln Y_{j}+\delta_{M} \ln d_{j}+\beta_{M} D V_{j}+u_{j} \\
\ln X_{j}=\ln K_{X}+\alpha_{X} \ln Y_{j}+\delta_{X} \ln d_{j}+\beta_{X} D V_{j}+u_{j}
\end{gathered}
$$

If the coefficient of the dummy variable is positive and significant, it means that there is enhanced trade between Turkey and that specific country group. Likewise, if the coefficient of the dummy variable is negative and significant, it means that there is retarded trade between Turkey and that specific country group.

In this study, Turkey's exports and imports volumes with the following specific country groups are examined:

- EU: European Union members as of 2004 (Austria, Belgium, Denmark, Finland, France, Germany, Greece, Ireland, Italy, Netherlands, Portugal, Spain, Sweden, United Kingdom)

- EXSOVIET: Former Soviet Union countries (Belarus, Estonia, Georgia, Latvia, Lithuania, Moldova, Russia, Ukraine)

- ISLAMIC: Islamic countries (Afghanistan, Albania, Algeria, Bangladesh, Egypt, Indonesia, Iran, Iraq, Jordan, Kuwait, Lebanon, Libya, Malaysia, Morocco, Oman, Pakistan, Palestine, Qatar, Saudi Arabia, Sudan, Syria, Tunisia, United Arab Emirates, Yemen)

- CA: Central Asian Turkic countries (Kazakhstan, Kyrgyzstan, Uzbekistan, Turkmenistan, Tajikistan, Azerbaijan)

\begin{tabular}{|c|c|c|}
\hline & IMPORTS & EXPORTS \\
\hline GROUP & Coefficient of DV & Coefficient of DV \\
\hline EU & insignificant & insignificant \\
\hline EXSOVIET & insignificant & insignificant \\
\hline ISLAMIC & insignificant & insignificant \\
\hline CA & significant and positive & significant and positive \\
\hline
\end{tabular}

Table 2: Results of country group analysis

According to the results summarized in Table 2, of the four specific country groups studied, Turkey has significantly higher trade volume in both directions only with the Central Asian countries as compared to the 
basic model's prediction. Clearly, Turkey has deep ties with the Central Asian countries regarding the common history that Turkish people originate from the region and then they migrated to Anatolia, and the Islamic religion and culture, as well as the Turkish language.

On the other hand, one surprising outcome is that there is no significantly higher trade with the EU countries, despite the fact that Turkey has entered Customs Union with the EU countries in 1995, which came into effect in 1996. This does not mean that Turkey's trade volume with the EU countries is low; in fact, Turkey has the largest trade volume in absolute terms with the EU countries. The trade volume is high and increasing over time just because the EU countries are geographically close to Turkey and they have high and increasing GDP levels. This conclusion is consistent with the findings of Antonucci and Manzocchi (2006). This result means that the establishment of the Customs Union or any other step already taken towards full membership into the EU did not statistically significantly increase the trade volume beyond the amount that the basic gravity model predicts with any country pair of similar distance and GDP levels. This conclusion can be rationalized by the fact that Turkey's main exports are agricultural products, whereas the Customs Union specifically excluded agricultural and service sectors.

\section{Conclusions}

The answer provided in this study to the question whether the gravity model is still adequate in explaining trade patterns in the era of globalization is a resounding yes: Gravity model, even in its basic form, is eternal. For the case of Turkey, in the years 1993-2008 and with respect to all the country pairs studied, the coeffiecients of GDP and of distance turned out to be statistically significant. Even though trade directions may have shifted from developed countries only to developing as well as less developed countries, their increased GDP levels are sufficient to explain this shift in the case of Turkey's trade volumes. Moreover, distance is still a very important factor in determining the trade volume despite the improvements in multi-modal transportation and logistics. This result is influenced by the fact that Turkey acts as a bridge between Europe, Asia and even Africa. In fact, Turkey is in the middle of a large trading region with diverse factor endowments that includes Europe, North Africa, Middle East, former Soviet Union countries and Central Asia, and hence may not feel the need to trade with far-away countries of the Americas, Far East or Oceania.

Considering the extended gravity model with specific country groups for the case of Turkey, the conclusion is that except for the Central Asian countries, Turkey's trade is not specialized with any particular country group. Clearly, Turkey has deep ties with the Central Asian countries regarding the common history that Turkish people originate from the region and then they migrated to Anatolia, and the Islamic religion and culture, as well as the Turkish language.

The 1995 Customs Union with the EU or any other step already taken towards full membership into the EU has not significantly increased Turkey's trade volume with the EU members over the amounts predicted by the basic version of the gravity model for any country pair of similar distance and GDP levels. This conclusion can be rationalized by the fact that Turkey's main exports are agricultural products, whereas the Customs Union specifically excluded agricultural and service sectors.

\section{References}

- $\quad$ Antonucci, D. and Manzocchi, S. (2006). "Does Turkey have a special trade relation with the EU?: A gravity model approach”, Economic Systems, Volume 30, Issue 2, Pages 157-169.

- $\quad$ Deardorff, A.V. (1995). "Determinants of bilateral trade: Does gravity work in a neoclassical world?". Number 5377 in NBER Working Paper Series. National Breau of Economic Research.

- Maddison, A. (2008). The World Economy: A Millenial Perspective. The World Bank.

- MapCrow (2011). http://www.mapcrow.info

- Poyhonen, P. (1963). "A tentative model for the volume of trade between countries". Weltwirtschaftliches Arschiv 90, 93.

- Tinbergen, J. (1962). "Shaping the world economy: Suggestions for an international policy". Kraus Reprint and Periodicals.

- Undersecretary of Turkish Foreign Trade (2011), http://www.dtm.gov.tr/dtmweb/index.cfm?action=detayrk\&yayinID=1 116\&icerikID=1225\&dil=TR (10.02.2011)

- United Nations National Accounts Database (2011), http://unstats.un.org/unsd/snaama/introduction.asp (10.02.2011)

- $\quad$ WTO (2008). International Trade Statistics 2008. 